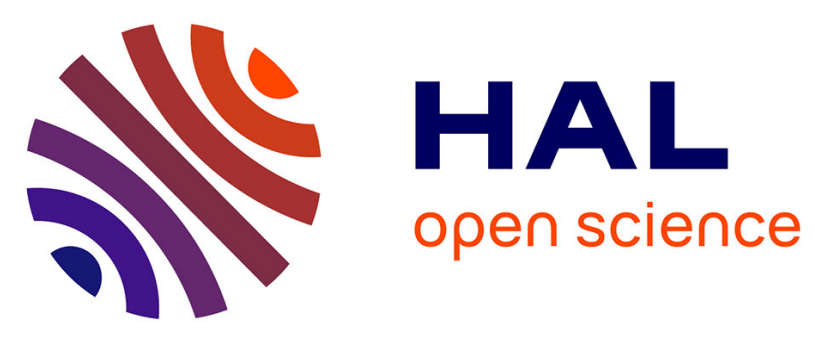

\title{
Impact of the annealing temperature on the optical performances of Er-doped Si-rich silica systems Impact of the annealing temperature on the optical performances of Er-doped Si-rich Silica systems
}

Sébastien Cueff, Christophe Labbé, Julien Cardin, Richard Rizk

\section{To cite this version:}

Sébastien Cueff, Christophe Labbé, Julien Cardin, Richard Rizk. Impact of the annealing temperature on the optical performances of Er-doped Si-rich silica systems Impact of the annealing temperature on the optical performances of Er-doped Si-rich Silica systems. IOP Conference Series: Materials Science and Engineering, 2009, 6 (1), pp.012021. 10.1088/1757-899X/6/1/012021 . hal-01216320

\author{
HAL Id: hal-01216320 \\ https://hal.science/hal-01216320
}

Submitted on 19 Oct 2015

HAL is a multi-disciplinary open access archive for the deposit and dissemination of scientific research documents, whether they are published or not. The documents may come from teaching and research institutions in France or abroad, or from public or private research centers.
L'archive ouverte pluridisciplinaire HAL, est destinée au dépôt et à la diffusion de documents scientifiques de niveau recherche, publiés ou non, émanant des établissements d'enseignement et de recherche français ou étrangers, des laboratoires publics ou privés. 
Impact of the annealing temperature on the optical performances of Er-doped Si-rich silica systems

This content has been downloaded from IOPscience. Please scroll down to see the full text. 2009 IOP Conf. Ser.: Mater. Sci. Eng. 6012021

(http://iopscience.iop.org/1757-899X/6/1/012021)

View the table of contents for this issue, or go to the journal homepage for more

Download details:

IP Address: 192.93.101.162

This content was downloaded on 16/10/2015 at 08:24

Please note that terms and conditions apply. 


\title{
Impact of the annealing temperature on the optical performances of Er-doped Si-rich Silica systems
}

\author{
S. Cueff, C. Labbé, J. Cardin, R. Rizk \\ Centre de Recherche sur les Ions, les Matériaux et la Photonique (CIMAP), \\ ENSICAEN, CNRS, CEA/IRAMIS, UCBN, 14050 CAEN cedex, FRANCE \\ E-mail: christophe.labbe@ensicaen.fr
}

\begin{abstract}
Series of Er-doped Si-rich silicon oxide (SRSO:Er) layers were grown by magnetron sputtering at different temperatures from ambient to $500^{\circ} \mathrm{C}$ and then annealed between $600^{\circ} \mathrm{C}$ and $1100^{\circ} \mathrm{C}$. They were characterized by spectroscopic and time-resolved photoluminescence (PL) measurements. Significant PL was detected at $1533 \mathrm{~nm}$ from the as-grown samples at $\mathrm{T} \geq 300^{\circ} \mathrm{C}$ excited by a non-resonant wavelength $(476 \mathrm{~nm})$, hence indicating the formation of $\mathrm{Si}$-based sensitizers during the growth process. The PL intensity and the decay lifetime of $\mathrm{Er}^{3+}$ ions were both greatly increased with the annealing temperature. An optimum temperature of annealing is obtained at $800^{\circ} \mathrm{C}$, which is expected to favor the formation of very dense and small sensitizers. The fraction of Er coupled to sensitizers was found nearly 6-7 times higher than that reported so far in the literature.
\end{abstract}

\section{Introduction}

The effective excitation cross section of $\mathrm{Er}^{3+}$ ions in $\mathrm{SiO}_{2}$ is increased by $10^{3}-10^{4}$ with the insertion of Si-based sensitizers in the matrix. It was shown that an indirect excitation of $\mathrm{Er}^{3+}$ ions occurs through Si nanoclusters (Si-nc) $[1,2]$. Such an energy transfer allows one to benefit from the broadband high absorbance of Si-nc for optical excitation and from the improved transport of carriers injected by electrical excitation. This paves the way to the achievement of $\mathrm{Er}^{3+}$ population inversion by either optical or electrical pumping for integrated photonics, such as planar amplifier, laser, etc. Recent studies reported that, in conventional SRSO:Er materials, only a small fraction $(<2 \%)$ of $^{3+}$ ions are effectively benefiting from the Si-nc-mediated excitation [3]. Such a low value is far from ensuring an inversion population of $\mathrm{Er}^{3+}$, but requires, on the contrary, more efforts and studies to enhance significantly the proportion of coupled Er in SRSO:Er samples. These latter are usually submitted to annealing processes to form Si nanoclusters ( $\mathrm{Si}-\mathrm{nc}$ ) as sensitizers, to remove non-radiative defects and to activate (optically) the $\mathrm{Er}^{3+}$ ions. Such a treatment may change, however, the structure of either the Si-based sensitizers or the $\mathrm{Er}^{3+}$ ions. This work aims at investigating the influence of growth and annealing temperature on the optical properties of the SRSO:Er layers and to correlate it to the proportion of Er coupled to sensitizers.

\section{Experimental techniques}

The samples were grown onto a p type $250 \mu$ m-thick silicon wafer with a $5 \mu$ m-thick $\mathrm{SiO}_{2}$ buffer layer. The deposition was made by the magnetron co-sputtering of three confocal cathodes: $\mathrm{SiO}_{2}, \mathrm{Si}$ and $\mathrm{Er}_{2} \mathrm{O}_{3}$, under plasma of pure Argon at a pressure of 2 mTorr. The substrate temperature $\left(T_{S}\right)$ was varied from room temperature (RT) to $600^{\circ} \mathrm{C}$. The annealing was achieved under a nitrogen flow, for temperatures $\left(T_{a}\right)$ varying from $600^{\circ} \mathrm{C}$ to $1100^{\circ} \mathrm{C}$ during 1 hour. The $\mathrm{Si}$ excess was estimated at about 
7.5 at $\%$ from the analyses of Fourier Transform InfraRed (FTIR) spectra. $\mathrm{Er}^{3+}$ concentration was measured by Secondary Ions Mass Spectroscopy (SIMS) and was found to be $2.2 \times 10^{20} \mathrm{~cm}^{-3}$. Visible and Infrared (IR) photoluminescence were obtained using the non-resonant $476 \mathrm{~nm}$ excitation wavelength from an $\mathrm{Ar}^{+}$laser. Time-resolved measurements were measured thanks to an oscilloscope.

\section{Results and discussion}

\subsection{As-deposited optical properties}

Significant Er emission was observed from the as-grown samples with $T_{S} \geq 300^{\circ} \mathrm{C}$, as illustrated by the typical spectrum displayed in Fig. 1 and recorded with non-resonant excitation wavelength (476 $\mathrm{nm})$. The detection of Er PL at both $1533 \mathrm{~nm}$ and $980 \mathrm{~nm}$ is indicative of the formation of Si-ncs acting as sensitizers during the grown process when performed with $T_{S} \geq 300^{\circ} \mathrm{C}$. This is supported by the visible PL band centered at $\sim 750 \mathrm{~nm}$ which can be attributed to Si-ncs. Similar Er PL features have been obtained earlier by our group on Er-doped SRSO samples grown with $T_{S}=500^{\circ} \mathrm{C}$ [4].

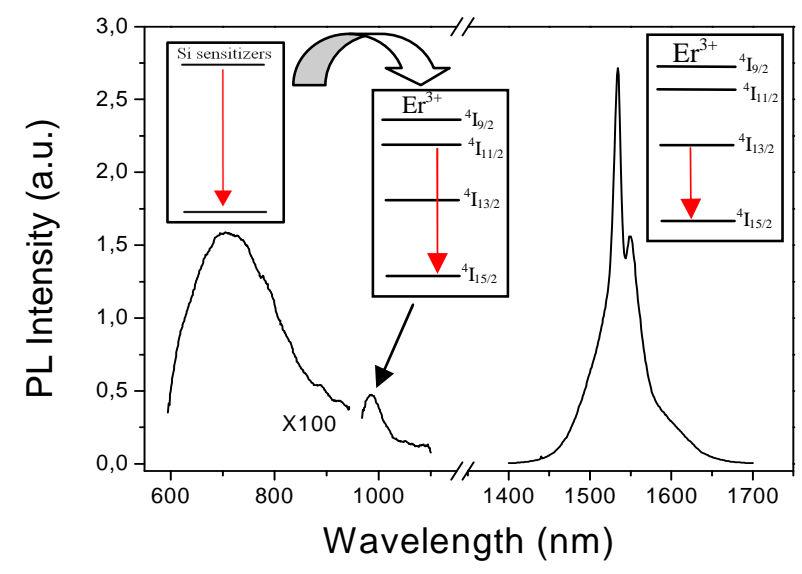

Figure 1.

PL spectrum of the 'as-deposited' SRSO:Er sample. Each electronic transition scheme is enclosed to its corresponding peak. In the range 600$1100 \mathrm{~nm}$, the PL was detected by a Photomultiplier tube while in the range 1400-1700 $\mathrm{nm}$ the PL was measured by a nitrogen-cooled $\mathrm{Ge}$ detector. The two detectors were calibrated to compare one with the other.

These observations reveal that the Si-based sensitizers are formed during the deposition process. Chosen $T_{S}$ are high enough to ensure the surface mobility of the adatoms and then the growth of sensitizers on the seeds available at the surface or near-surface region of the growing layer. These Sibased entities play the role of efficient sensitizers before any annealing treatment, hence reflecting a favorable environment and good quality matrix. Indeed, the $\mathrm{Er}^{3+}$ lifetime was found to be $\sim 4 \mathrm{~ms}$ at $1533 \mathrm{~nm}$ which is a notably high value for a non-annealed sample, compared to that reported by other groups for annealed samples [5,6]. The lifetime is well fitted by a single exponential decay, suggesting a single kind of site for emitting erbium ions.

\subsection{Enhancement of the optical properties by annealing treatment}

Figure 2 describes the evolution of the integrated intensity in function of $T_{a}$ for the two main PL features: the $\mathrm{Er}^{3+}-\mathrm{PL}$ around $1533 \mathrm{~nm}$ and the Si-nc-PL around $700 \mathrm{~nm}$. The annealing treatment improves gradually the $\mathrm{Er}^{3+}$ emission until 3 times that recorded from the as-deposited sample when $T_{a}$ reaches $800-900^{\circ} \mathrm{C}$. At higher $T_{a}$ values, the $\mathrm{Er}^{3+}$ emission shows a sharp decrease down to the tenth of the maximum. For the other feature, the Si-related emission appears almost constant for $T_{a} \leq 1000^{\circ} \mathrm{C}$, before increasing drastically when $T_{a}$ is further increased to $1100^{\circ} \mathrm{C}$. Such an increase of $T_{a}$ has apparently some counterbalancing effects on the PL of Si-ncs and $\mathrm{Er}^{3+}$ ions, suggesting some changes in the transfer mechanism and material structure in this range of annealing. The behavior of the $\mathrm{Er}^{3+}$ emission lifetime upon annealing temperature is shown in figure 3 . The lifetime is increased with $T_{a}$ from about $4 \mathrm{~ms}$ to a plateau at $\sim 6 \mathrm{~ms}$ for annealing between 700 and $900^{\circ} \mathrm{C}$. 


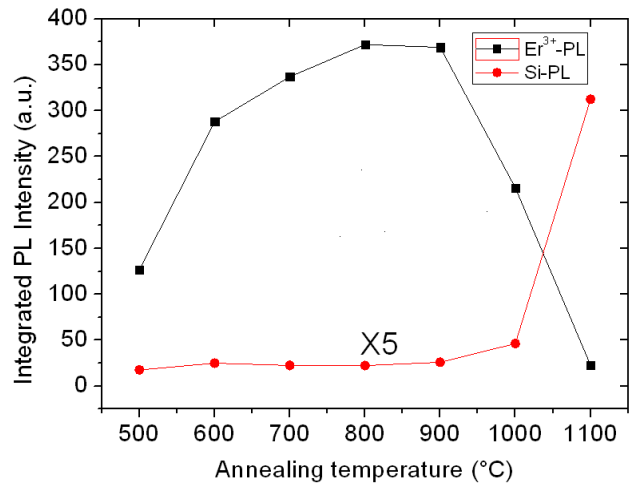

Figure 2. Integrated PL intensity versus annealing temperatures

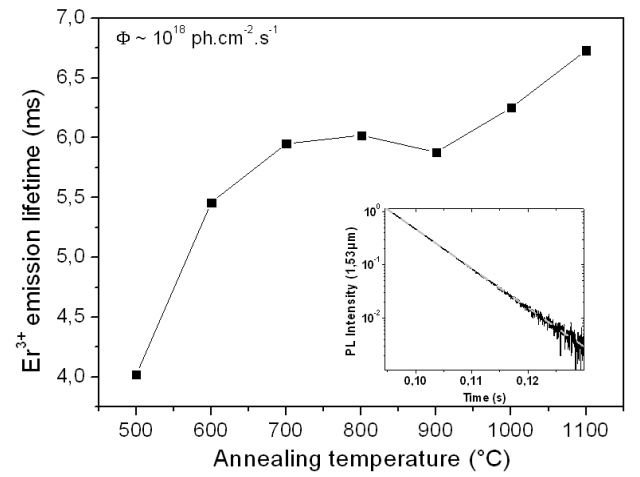

Figure 3. Evolution of the $\mathrm{Er}^{3+}$ emission lifetime as a function of the annealing temperatures. The inset shows the characteristic single-exponential behaviour of time-resolved PL spectroscopy.

It shows an additional increase to $\sim 7 \mathrm{~ms}$ when $T_{a}$ is further raised to $1100^{\circ} \mathrm{C}$. The behaviour of the lifetime is consistent with the evolutions of the two emissions shown in Fig. 2. The annealing from 600 to $900^{\circ} \mathrm{C}$ is expected to lead to the following: (i) the growth of additional sensitizers for more coupling with Er ions, especially as the separating distance should be as low as $\sim 0.5 \mathrm{~nm}$ for an optimum energy transfer [7,3], (ii) the reduction of the non-radiative channels and then the increase of the lifetime, as observed. On the other hand, the annealing at $T_{a}$ higher than $900^{\circ} \mathrm{C}$ may induce some structural changes such as: (i) the coalescence phenomenon that takes place in this range of temperature [8] and which results in larger Si-nc at the expense of their density and then of their coupling with the Er ions, (ii) the diffusion and segregation of Er which might occur in this range of $T_{a}$ for our Er content, as demonstrated elsewhere [6], (iii) the enhanced diffusion mechanism of other elements such as oxygen could contribute to feed the Er surrounding with more oxygen [9] for further raise of the lifetime. These two suggestions of nanoclusters coalescence and Er segregation can consistently explain the drastic decrease of the Er PL and the counterpart sharp increase of Si-nc PL. The segregation of Er at high values of $T_{a}$ is supported by the comparison of the evolution of Er PL for $T_{a}=1100^{\circ} \mathrm{C}$ to that of the as-deposited sample according to the excitation photon-flux $\phi$ (Fig. 4).

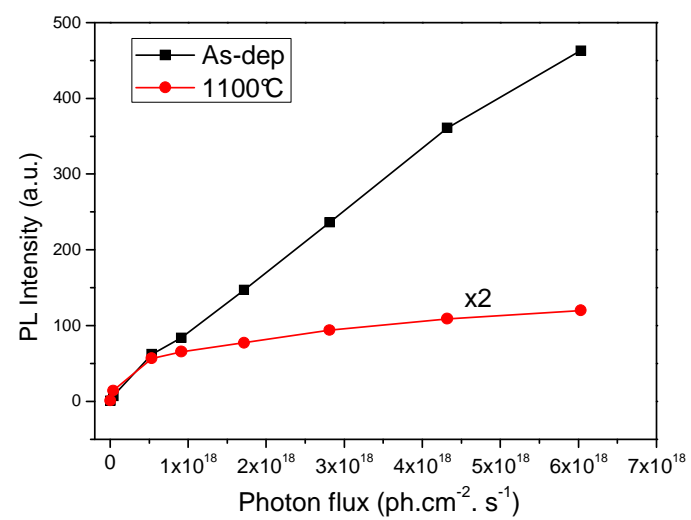

Figure 4. $\mathrm{PL}$ intensity of $\mathrm{Er}^{3+}$ emission (at $1.53 \mu \mathrm{m}$ ) as a function of the photon flux for as-deposited sample and $1100^{\circ} \mathrm{C}$ annealing sample.

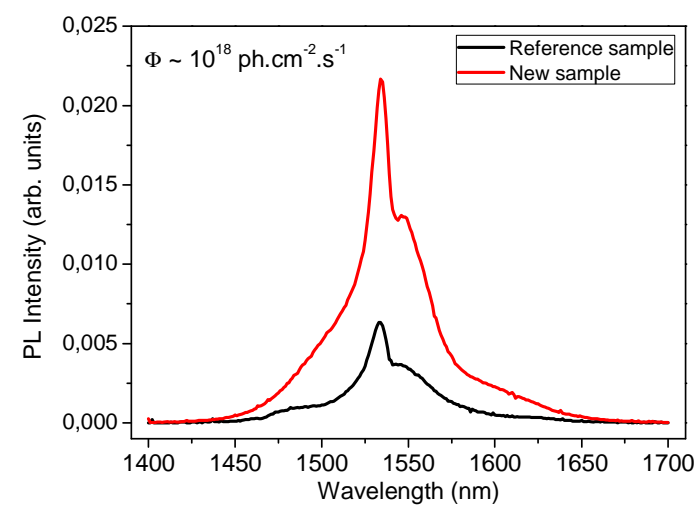

Figure 5. Comparison of the PL Intensity from a reference sample and from our best sample. The reference sample as a known coupling fraction $(1.76 \%)$

Indeed, the rapid saturation of the former when $\phi$ is increased is indicative of an agglomeration of Erbium, as already observed for Er-doped $\mathrm{SiO}_{2}$ [10] and Er-doped SRSO [11], whereas the latter evolves almost linearly with $\phi$. The other impact of $T_{a}=1100^{\circ} \mathrm{C}$ lies in the formation of large Si-ncs 
that can more easily crystallize and would be limited by a sharp $\mathrm{Si} / \mathrm{SiO}_{2}$ interface containing relatively small amount of defects. They are, therefore, emitting more efficiently in the visible range with a peak shifting towards lower energy (750 nm vs $700 \mathrm{~nm}$ for as-deposited, not shown). This explain the abrupt increase of its emission for $T_{a}=1100^{\circ} \mathrm{C}$. These structural changes have also an impact on the evolution of the lifetime. It was reported recently that the Er radiative lifetime is affected by the proximity and the size of Si-nc [12]. Ref 12 demonstrates that the shortening of the Er-nanocluster spacing and the size increase of the nanocluster, lead to the lowering of the radiative decay time. In this connection, one can, therefore, consider that the increase of the Er lifetime, particularly for $T_{a}>$ $900^{\circ} \mathrm{C}$ (Fig. 3) can also be due to the increasingly reduced impact of Si-nc which grows further away from Er ions.

Finally, to estimate roughly the fraction of coupled Er in our best sample $\left(T_{S}=500^{\circ} \mathrm{C}, T_{a}=900^{\circ} \mathrm{C}\right)$, we have compared its Er PL to that of a reference sample described in Ref.3 (figure 5) and whose fraction of coupled Er is only $1.7 \%$. This latter contains $4 \times 10^{20} \mathrm{Er} / \mathrm{cm}^{3}$, the same amount of Si excess (7.5 at. $\%)$ and was annealed at the same $T_{a}$. At a same excitation flux $\left(\phi \sim 10^{18} \mathrm{ph} / \mathrm{cm}^{2} . \mathrm{s}\right)$, their PL intensity can be compared following $I_{P L} \propto \sigma_{\text {eff }} \phi N_{E r, c} . \tau_{d e d} \tau_{r a d}$ where $\sigma_{\text {eff }}$ is the effective excitation cross section, $\tau_{\text {dec }}$ is the time decay and $\tau_{\text {rad }}$ is the radiative lifetime. $N_{E r, c}$ is the concentration of $\mathrm{Er}^{3+}$ ions coupled to $\mathrm{Si}$-nc, which is equal to about $6.8 \times 10^{18} \mathrm{~cm}^{-3}$ for the reference sample. By comparing the ratio of their intensities ( 3.6), their $\sigma_{\text {eff }}\left(3.1 \times 10^{-17} \mathrm{~cm}^{-2}\right.$ vs $\left.\sim 2.3 \times 10^{-17} \mathrm{~cm}^{2}\right)$, their $\tau_{\text {dec }}(6 \mathrm{~ms}$ vs $3.6 \mathrm{~ms})$ and their $\tau_{\text {rad }}$ $(12 \mathrm{~ms} v \mathrm{vs} 9 \mathrm{~ms})$ as can be deduced from [13] on the basis of their refractive index (1.56 vs 1.52), one could estimate $N_{E r, c}$ for our best sample to about $2.6 \times 10^{19} \mathrm{~cm}^{-3}$. This value represents nearly $12 \%$ of the total Er content $\left(2.2 \times 10^{20} \mathrm{~cm}^{-3}\right)$, i.e. 6-7 higher than that of the reference sample at this photon flux.

\section{Conclusions}

An efficient indirect excitation of Erbium ions via Si sensitizers was obtained before any annealing treatment, while the optimum Er emission is obtained after annealing in the $700-900^{\circ} \mathrm{C}$ range. The corresponding lifetime is found as high as $4 \mathrm{~ms}$ for the as-grown, and increases significantly with annealing. Structural changes are noticed after annealing at more $1000^{\circ} \mathrm{C}$. A rough estimate of the fraction of coupled Er has allowed to notice that their proportion was improved from about $1.7 \%$ for earlier samples to nearly $12 \%$.

Acknowledgments This work is supported by the European Project LANCER (FP6-IST-033574)

\section{References}

[1] Kenyon A J, Trwoga P F, Federighi M, and Pitt C W 1994 J. Phys.: Condens. Matter 6 L319

[2] Fujii M, Yoshida M, Kanzawa Y, Hayashi S and Yamamoto K 1997 Appl. Phys. Lett. 711198

[3] Garrido B, Garcia C, Seo S, Pellegrino P, Navarro-Urrios D, Daldosso N, Pavesi L, Gourbilleau F, and Rizk R 2007 Phys. Rev. B 76245308

[4] Hijazi K, Khomenkova L, Gourbilleau F, Cardin J and Rizk R 2009 J. Lum. In Press

[5] Savchyn O, Ruhge F R, Kik P G, Todi R M, Coffey K R, Nukala H and Heinrich H 2007 Phys. Rev. B 76195419

[6] Wora Adeola G, Rinnert H, Miska P and Vergnat M 2007 J. Appl. Phys. 102053515

[7] Gourbilleau F, Madelon R, Dufour C and Rizk R 2005 Opt. Mater. 27 868-875

[8] Jambois O, Rinnert H, Devaux X and Vergnat M, 2006 J. Appl. Phys. 100, 123504

[9] Maurizio C, Iacona F, D'Acapito F, Franzo G and Priolo F 2006 Phys. Rev. B 74205428

[10] Polman A, Jacobson D C, Eaglesham D J, Kistler R C and Poate J M, 1991 J. Appl. Phys. 70 3778-3784.

[11] Pellegrino P, Garrido B, Arbiol J, Garcia C, Lebour Y and Morante J R 2006 Appl. Phys. Lett. 88121915

[12] Horak P, Loh W H and Kenyon A J 2009 Opt. Exp. 17 906-911

[13] Daldosso N, Navarro-Urrios D, Melchiorri M, Pavesi L, Sada C, Gourbilleau F and Rizk R 2006 Appl. Phys. Lett. 8816190 